\title{
Increased tolerability of bimonthly 12-hour timed flat infusion 5-fluorouracil/irinotecan regimen in advanced colorectal cancer: A dose-finding study
}

\author{
C. FICORELLA ${ }^{1}$, E. RICEVUTO ${ }^{1}$, M.F. MORELLI ${ }^{1}$, R. MORESE ${ }^{1}$, K. CANNITA ${ }^{1}$, G. CIANCI ${ }^{1}$, G. PORZIO ${ }^{1}$, \\ Z.C. DI ROCCO ${ }^{1}$, F. DE GALITIIS ${ }^{1}$, M. DE TURSI ${ }^{2}$, N. TINARI ${ }^{2}$, S. IACOBELLI ${ }^{2}$ and P. MARCHETTI ${ }^{1}$ \\ ${ }^{1}$ Medical Oncology, Department of Experimental Medicine, University of L'Aquila; ${ }^{2}$ Department of Oncology \\ and Neurosciences, Section of Medical Oncology, University G. D'Annunzio, Chieti, Italy
}

Received June 21, 2005; Accepted August 19, 2005

\begin{abstract}
A dose-finding study was designed to determine the maximum tolerated dose (MTD) of a bimonthly 12-h (10:00 p.m to 10:00 a.m), timed flat infusion (TFI) of 5-fluorouracil (5-FU) plus irinotecan (CPT-11), without leucovorin (LV), for metastatic colorectal carcinoma (CRC). A total of 33 patients were treated. Seven dose levels included a fixed CPT-11 dose of $180 \mathrm{mg} / \mathrm{m}^{2}$ on days 1 and 15 $\left(\mathrm{d}_{1,15}\right)$ and escalating doses of 5-FU $600-1200 \mathrm{mg} / \mathrm{m}^{2}$ on days 1-4 and 15-18 ( $\left.\mathrm{d}_{1-4,15-18}\right)$. Dose-limiting toxicities (DLTs) were: grade 3-4 non-hematologic, grade 4 hematologic and any toxicity causing a more than a 2 -week delay in treatment. The MTD was reached at the seventh dose level. DLTs were observed in 5/8 patients (63\%): G3 diarrhea, 2 patients, associated with G3 mucositis in one instance; G4 neutropenia, 2 patients, associated with severe asthenia in 1 patient; G3 hand-foot syndrome, 1 patient. The recommended doses (RDs) were established at the sixth dose level: 5-FU, $1100 \mathrm{mg} / \mathrm{m}^{2} / \mathrm{d}_{1-4,15-18} ;$ CPT-11 $180 \mathrm{mg} / \mathrm{m}^{2} / \mathrm{d}_{1,15}$ [5-FU and CPT-11 dose intensity (DI), 2200 and $90 \mathrm{mg} / \mathrm{m}^{2}$ per week (w), respectively]. At the recommended dose, the DLTs in 38 cycles were: mucositis, 2 cycles $(5 \%)$; afebrile G4 neutropenia and hand-foot syndrome, 1 cycle (3\%). In 24 assessable patients, the overall response rate was $37.5 \%$. The present CPT-11/5-FU schedule is highly tolerable in an outpatient setting using the highest recommended 5-FU dose effective in advanced CRC.
\end{abstract}

\section{Introduction}

5-FU infusion shows equivalent efficacy (response rate 22\%), but appears slightly superior to LV-5-FU bolus in terms of

Correspondence to: Dr Corrado Ficorella, Department of Experimental Medicine, University of L'Aquila, Via Vetoio, Coppito, L'Aquila 67100, Italy

E-mail: ficorella@interfree.it

Key words: irinotecan, 5-fluorouracil, advanced colorectal cancer survival (12.1 vs 11.3 months; $\mathrm{p}<0.04)$ given on a weekly or daily $x 5$ schedule $(1,2)$. Preclinical data suggest that an infusion of 5-FU acts through thymidylate synthase inhibition, while bolus injection inhibits RNA synthesis (3). Compared to the bolus schedule, $24 \mathrm{~h}$ continuous infusion (C.I.) of 5-FU is less frequently associated with grade (G) 34 neutropenia ( $4 \%$ vs. $31 \%$ ), but more frequently associated with G3-4 hand-foot (H-F) syndrome (34\% vs $13 \%)$; no difference exists between the two schedules in terms of non-hematological toxicity (4). 5-FU is still considered a mainstay in the treatment of colorectal cancer, especially in combination with new molecules such as CPT-11 and oxaliplatin $(5,6)$.

In metastatic $\mathrm{CRC}$ patients, $\mathrm{CPT}-11$ showed a response rate of $11-17 \%$ in 5-FU-resistant disease and $26 \%$ in untreated patients $(7,8)$. Moreover, CPT-11 significantly improved survival when compared to the best supportive care or 5-FU infusion $(9,10)$. The DLTs of CPT-11 are delayedonset diarrhea (G3-4, 20\% of patients) and neutropenia (G3-4, $17 \%$ of patients) (11).

The mechanism of action of CPT-11 and its efficacy in pretreated as well as in naive patients provided the rationale for CPT-11/5-FU combination therapies in metastatic CRC. Two studies demonstrated that CPT-11/5-FU given as firstline treatment improves tumor control and increases overall survival with respect to bolus or infusional 5-FU/LV $(12,13)$. Diarrhea and neutropenia represented the DLTs of different schedules. At present, only schedules including infusions of 5-FU are considered for phase III studies, due to the consistent toxicity observed for bolus 5-FU-based combinations $(14,15)$. The aim of the present dose-finding study, which contemplates infusional 5-FU plus bolus CPT-11, was to further increase tolerability and DI of 5-FU by using a bimonthly 12 -h (10:00 p.m to 10:00 a.m) timed flat infusion (TFI) of 5-FU without LV. LV modulation of infusional 5-FU, alone or in combination with new drugs such as CPT-11, increases gastrointestinal toxicity without increasing clinical benefit. The 12-h (10:00 p.m to 10:00 a.m) TFI/FU infusion was chosen to exploit the increased activity of the mononuclear cells of dehydropyrimidine dihydrogenase (DPD), the enzyme involved in 5-FU intracellular catabolism, and the reduced proliferation of normal target tissue, such as 

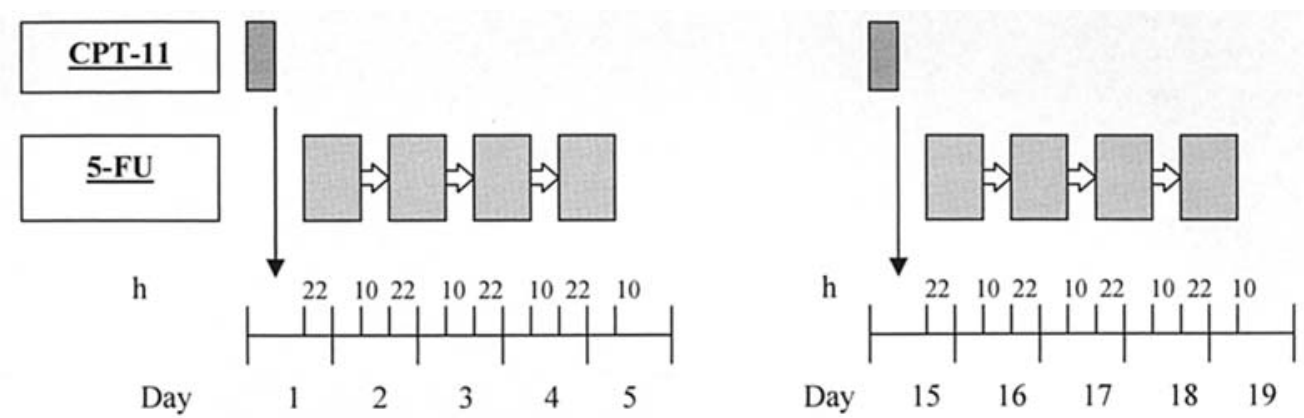

Figure 1. Treatment schedule. Treatment comprised $180 \mathrm{mg} / \mathrm{m}^{2}$ CPT- 11 over $90 \mathrm{~min}$ was given on days 1 and 15 , and $600-1200 \mathrm{mg} / \mathrm{m}^{2} / \mathrm{d} 5-\mathrm{FU}$ in a flat $12-\mathrm{h}$ infusion on days 1-4 and 15-18 were administered in a cycle of 4 weeks. Boxes, interval-time of drug infusion; arrows, interval-time without infusion.

the bone marrow and oral/rectal mucosa, during the evening hours (16-18). This phase I study evaluates DLT and determines the RD of this TFI/FU schedule in metastatic CRC.

\section{Patients and methods}

Inclusion criteria were: histologically confirmed diagnosis of CRC with clinical evidence of metastatic disease; age between 18 and 75 years; World Health Organization (WHO) performance status $2\left(3 \times 10^{3} / \mathrm{mm}^{3} \mathrm{WBC}\right.$ count, $1.5 \times 10^{3} / \mathrm{mm}^{3}$ neutrophils, $100 \times 10^{3} / \mathrm{mm}^{3}$ platelets, $10 \mathrm{~g} / \mathrm{dl}$ hemoglobin, $1.3 \mathrm{mg} / \mathrm{dl}$ serum creatinine, $1.5 \mathrm{mg} / \mathrm{dl}$ serum bilirubin, AST and ALT (2.5-fold the normal value; life expectancy of more than 3 months. Pregnant and breast-feeding women were excluded from the study, as were patients with a history of myocardial infarction. Previous chemotherapy or radiotherapy was required to be completed at least 6 months before entering the study. The study was approved by the Local Ethics Committee; patients were informed of the investigational nature of the study and provided written informed consent.

Medical history, physical examination, and routine laboratory studies were recorded prior to the initiation of treatment and at each cycle thereafter. All patients had imaging of measurable or assessable disease by computed tomographic (CT) scans of the abdomen/pelvis and chest, an electrocardiogram, and assessment of tumor markers (CEA, CA19-9) at baseline and every 3 cycles of treatment thereafter.

In this phase I unblinded, single-arm, dose-escalation study, 5-FU in combination with CPT-11 was administered according to the bimonthly schedule (Fig. 1) of: CPT-11 (Campto $^{\mathrm{TM}}$, Aventis) administered over $90 \mathrm{~min}$ as an intravenous infusion in $250 \mathrm{ml}$ of $\mathrm{NaCl} 0.9 \%$ at the fixed dose of $180 \mathrm{mg} / \mathrm{m}^{2}$ on days 1 and 15 , every 4 weeks; 5 -FU (Fluorouracil Teva $^{\mathrm{TM}}$, Teva) over a 12-h (from 10:00 p.m to 10:00 a.m.) timed flat infusion starting at a dose of $600 \mathrm{mg} / \mathrm{m}^{2}$ on days 1-4 and 15-18, every 4 weeks. Placement of an implanted venous access device was required. 5-FU was administered by means of a portable pump (CADD Plus, Sevit). No prophylactic treatment with granulocyte colonystimulating factor was used. Treatment was routinely administered on an outpatient basis.

$5-\mathrm{FU}$ was escalated according to a $100 \mathrm{mg} / \mathrm{m}^{2} /$ day (d) increase for each dose level. The planned 5-FU dose levels were $600,700,800,900,1000,1100$, and $1200 \mathrm{mg} / \mathrm{m}^{2} / \mathrm{d}$.
Table I. Clinical features of enrolled patients.

\begin{tabular}{lc}
\hline & No. $(\%)$ \\
\hline No. of patients & 33 \\
Sex & \\
$\quad$ M/F & $14 / 19$ \\
Age, years & \\
$\quad$ Median & 65 \\
$\quad$ Range & $40-75$
\end{tabular}

${ }^{a}$ WHO performance status

0

1-2

Primary tumor

Colon

Rectum

No. of involved sites

1

$\geq 2$

Sites of metastases

Liver

Lung

Lymph nodes

Local

Other

Previous chemotherapy

Adjuvant

Advanced disease

Previous radiotherapy

4 (12)

${ }^{\mathrm{a}}$ WHO, World Health Organization.

The dose-escalation strategy combined the intra- and inter-patient approach (19). Intra-patient dose-escalation was considered in order to avoid under-treatment of patients by using a fixed dose of 5-FU. In the absence of DLT, 3 patients treated at the previous level and 3 untreated patients were entered at each dose level. This approach specifically 
Table II. Observed dose-limiting toxicities (DLTs) in enrolled patients, according to administered dose levels.

\begin{tabular}{|c|c|c|c|c|c|c|c|c|c|c|c|c|c|c|c|}
\hline \multirow[b]{2}{*}{$\begin{array}{l}\text { Dose } \\
\text { levels }\end{array}$} & \multirow[b]{2}{*}{$\begin{array}{l}5-\mathrm{FU} \\
\mathrm{mg} / \mathrm{m}^{2}\end{array}$} & \multirow[b]{2}{*}{$\begin{array}{c}5-\mathrm{FU} \\
\mathrm{DI}\end{array}$} & \multirow[b]{2}{*}{$\begin{array}{l}\text { Patients }^{\mathrm{a}} \\
\text { (new) }\end{array}$} & \multirow[b]{2}{*}{$\begin{array}{l}\text { No. of } \\
\text { cycles }\end{array}$} & \multirow{2}{*}{$\begin{array}{l}\text { No. of } \\
\text { Pts }^{b} \\
(\%)\end{array}$} & \multicolumn{2}{|c|}{$\begin{array}{c}\text { G3-4 } \\
\text { diarrhea }\end{array}$} & \multicolumn{2}{|c|}{$\begin{array}{c}\text { G4 } \\
\text { neutropenia }\end{array}$} & \multicolumn{2}{|c|}{$\begin{array}{c}\text { G3-4 } \\
\text { mucositis }\end{array}$} & \multicolumn{2}{|c|}{$\begin{array}{c}\mathrm{H}-\mathrm{F}^{\mathrm{c}} \\
\text { syndrome }\end{array}$} & \multicolumn{2}{|c|}{$\begin{array}{c}\text { Severe } \\
\text { asthenia }\end{array}$} \\
\hline & & & & & & $\begin{array}{l}\text { Pts } \\
(\%)\end{array}$ & $\begin{array}{c}\text { Cycles } \\
(\%)\end{array}$ & $\begin{array}{l}\text { Pts } \\
(\%)\end{array}$ & $\begin{array}{c}\text { Cycles } \\
(\%)\end{array}$ & $\begin{array}{l}\text { Pts } \\
(\%)\end{array}$ & $\begin{array}{c}\text { Cycles } \\
(\%)\end{array}$ & $\begin{array}{l}\text { Pts } \\
(\%)\end{array}$ & $\begin{array}{c}\text { Cycles } \\
(\%)\end{array}$ & $\begin{array}{l}\text { Pts } \\
(\%)\end{array}$ & $\begin{array}{c}\text { Cycles } \\
(\%)\end{array}$ \\
\hline I & 600 & 1200 & $5(5)$ & 5 & - & - & - & - & - & - & - & - & - & - & - \\
\hline II & 700 & 1400 & $11(6)$ & 15 & $3(27)$ & $2(18)$ & $2(13)$ & - & - & - & - & - & - & $1(9)$ & $1(7)$ \\
\hline III & 800 & 1600 & $15(5)$ & 18 & $1(7)$ & - & - & $1(7)$ & $1(5)$ & - & - & - & - & - & - \\
\hline IV & 900 & 1800 & $15(3)$ & 21 & $1(7)$ & - & - & - & - & - & - & $1(7)$ & $1(5)$ & - & - \\
\hline $\mathrm{V}$ & 1000 & 2000 & $20(8)$ & 30 & $5(20)$ & $4(20)$ & $4(13)$ & $1(5)$ & $1(3)$ & $1(5)$ & $1(3)$ & - & - & $1(5)$ & $1(3)$ \\
\hline VI & 1100 & 2200 & $18(6)$ & 38 & $3(17)$ & - & - & $1(6)$ & $1(3)$ & $2(11)$ & $2(5)$ & $1(6)$ & $1(3)$ & - & - \\
\hline \multirow[t]{2}{*}{ VII } & 1200 & 2400 & $8(0)$ & 19 & $5(63)$ & $2(25)$ & $2(11)$ & $2(25)$ & $2(11)$ & $1(13)$ & $1(5)$ & $1(13)$ & $1(5)$ & $1(13)$ & $1(5)$ \\
\hline & & & $92(33)$ & 146 & $18(20)$ & $8(9)$ & $8(5)$ & $5(5)$ & $5(3)$ & $4(4)$ & $4(3)$ & $3(3)$ & $3(2)$ & $3(3)$ & $3(2)$ \\
\hline
\end{tabular}

${ }^{a}$ Intra- and inter-patient dose-escalation; 'batients; 'hand-foot syndrome. DI, dose intensity; DLTs, dose-limiting toxicities; 5-FU, 5-fluorouracil; new, newly added patients; Pts, patients.

addresses the issue of toxicity in pretreated or newly treated patients at increasing 5-FU doses. If 1 or 2 patients experienced a DLT, a second cohort was treated at the same dose level. If no more than 2 of 6 patients experienced a DLT, the next cohort of patients was treated at the subsequent dose level. The MTD was defined as the dose at which at least $50 \%$ of the patients developed DLT. Other patients were then enrolled at the dose level immediately below the MTD to confirm it as the RD for further phase II studies.

Patients were evaluated for toxicity every 2 weeks according to National Cancer Institute Common Toxicity Criteria (NCI-CTC). Reported toxicities were the worst observed at each treatment cycle (two 5-FU/CPT-11 administrations). DLT was defined as G3 or G4 non-hematological toxicity (except nausea or vomiting), G4 neutropenia, febrile neutropenia or other hematological G4 toxicity or any toxicity determining a treatment delay longer than 2 weeks. In case of DLT, treatment was continued at the dose level immediately below. In the presence of diarrhea, mucositis, or myelosuppression on the day of scheduled treatment (NCICTC grade $>1$ ), therapy was delayed until full recovery.

Tumor imaging was repeated every 3 treatment cycles (12 weeks). Tumor response was assessed and defined according to the WHO response criteria; objective responses were confirmed every 3 cycles. Time to disease progression and survival were assessed using the Kaplan-Meier method.

\section{Results}

Consecutive metastatic CRC patients meeting eligibility criteria $(n=33)$ were enrolled by the Operative Unit of Medical Oncology, at the University of L'Aquila. A summary of patient baseline clinical features are shown in Table I. Median age was 65 years. Twenty-two patients had received at least one previous 5-FU-based chemotherapy regimen: 11 as adjuvant treatment (10 LV-5-FU bolus; 1 raltitrexed) and 11 for advanced disease (6; 5-FU-C.I.; 4 oxaliplatin/5-FUC.I.; 1 methotrexate/5-FU bolus).
The median number of cycles administered for each patient was 4 (range 1-9). The median number of dose levels achieved per patient was 3 (range, 1-6), and 146 cycles (99\%) were assessable as one patient refused his last cycle of therapy. Table II describes the observed DLTs in treated patients, and cycles were administered according to dose levels.

MTD was reached at the seventh dose level (5-FU DI $2400 \mathrm{mg} / \mathrm{m}^{2} / \mathrm{w}$ and CPT-11 DI $90 \mathrm{mg} / \mathrm{m}^{2} / \mathrm{w}$ ); 8 patients, all previously treated even at the lower dose level, reached this dose level for a total of 19 evaluable cycles; no new patients were enrolled at this dose level. DLTs were observed in 5/8 patients (63\%): 2 patients $(25 \%)$ experienced G3 diarrhea, associated with G3 mucositis in one patient; 2 patients (25\%) experienced G4 neutropenia, with 1 case associated to severe and long-lasting asthenia, accounting for a 2-week delay in chemotherapy; 1 patient (13\%) had G3 hand-foot (H-F) syndrome. These 5 patients received subsequent cycles at the sixth dose level without showing DLTs. In the 19 evaluable cycles at the seventh dose level, the prevalence of DLTs was: neutropenia, 2 cycles (11\%); diarrhea, 2 cycles (11\%); asthenia, 1 cycle $(5 \%)$; mucositis, 1 cycle $(5 \%)$; and $\mathrm{H}-\mathrm{F}$ syndrome, 1 cycle $(5 \%)$.

The sixth dose level (5-FU/DI $2200 \mathrm{mg} / \mathrm{m}^{2} / \mathrm{w}$ and CPT-11/DI $90 \mathrm{mg} / \mathrm{m}^{2} / \mathrm{w}$ ) represented the RD, and 18 patients were treated at this dose level (6 newly treated patients and 12 pretreated at lower dose levels) for a total of 38 evaluable cycles. DLTs were observed in 3/18 (17\%) patients: G3 mucositis in 1 of the 6 newly treated patients; G3 mucositis and G3 H-F syndrome in 1 of 12 dose-escalating patients; and afebrile G4 neutropenia in 1 patient after 8 doseescalation cycles. The DLTs observed in 38 cycles were: mucositis, 2 cycles (5\%); afebrile G4 neutropenia and $\mathrm{H}-\mathrm{F}$ syndrome, 1 cycle $(3 \%)$.

Cumulatively observed DLTs in 146 cycles were: diarrhea, 5\% (8 cycles); neutropenia, 3\% (5 cycles); mucositis, 3\% (4 cycles); H-F syndrome, 2\% (3 cycles); asthenia, 2\% (4 cycles); and vomiting, $1 \%$ (2 cycles). In particular, G3-G4 diarrhea was observed at different dose levels (II, V and VII). 
Table III. 5-FU dose intensity received and total dose.

\begin{tabular}{lcr}
\hline & Median (range) & Average $($ C.I. $\alpha 0.05)$ \\
\hline Dose intensity/cycle $\left(\mathrm{mg} / \mathrm{m}^{2} / \mathrm{w}\right)$ & $2000(933-2400)$ & $1872( \pm 58)$ \\
Dose intensity $/$ patient $\left(\mathrm{mg} / \mathrm{m}^{2} / \mathrm{w}\right)$ & $1866(1200-2300)$ & $1850( \pm 102)$ \\
Total dose $\left(\mathrm{mg} / \mathrm{m}^{2}\right)$ & $28000(6400-68000)$ & $34339( \pm 6375)$ \\
\hline
\end{tabular}

Table IV. Phase I studies of CPT-11 and 5-FU infusion in advanced colorectal cancer.

\begin{tabular}{|c|c|c|c|c|c|c|c|}
\hline \multirow[b]{2}{*}{ Author } & \multirow[b]{2}{*}{$\begin{array}{c}\text { No. of } \\
\text { pts }\end{array}$} & \multirow[b]{2}{*}{ 5-FU schedule } & \multicolumn{3}{|c|}{ Recommended DI } & \multicolumn{2}{|r|}{ DLTs } \\
\hline & & & $\begin{array}{c}5-\mathrm{FU} \\
\mathrm{mg} / \mathrm{m}^{2} / \mathrm{w}\end{array}$ & $\begin{array}{c}\text { CPT-11 } \\
\mathrm{mg} / \mathrm{m}^{2} / \mathrm{w}\end{array}$ & $\begin{array}{c}\mathrm{LV} \\
\mathrm{mg} / \mathrm{m}^{2}\end{array}$ & MTD & Recommended dose \\
\hline Vanhoefer et al, 1999 & 26 & C.I. & 2267 & 80 & 500 & Diarrhea & Diarrhea \\
\hline Ducreux et al, 1999 & 55 & Bolus + C.I $I_{22-h}$ & $400+600$ & $90-100$ & 200 & $\begin{array}{l}\text { Diarrhea } \\
\text { Diarrhea }\end{array}$ & $\begin{array}{l}\text { Neutropenia } \\
\text { Neutropenia }\end{array}$ \\
\hline Garufi et al, 2001 & 26 & C.I. chrono & 1166 & 108 & 200 & Diarrhea & Neutropenia \\
\hline Falcone et al, 2001 & 33 & C.I. & 1167 & 133 & 250 & Diarrhea & Neutropenia \\
\hline Kakolyris et al, 2001 & 42 & C.I. & 600 & 87 & - & $\begin{array}{c}\text { Diarrhea } \\
\text { Neutropenia }\end{array}$ & $\begin{array}{l}\text { Diarrhea } \\
\text { Mucositis } \\
\text { Neutropenia }\end{array}$ \\
\hline Present study & 33 & C.I.12-h & 2200 & 90 & - & $\begin{array}{c}\text { Diarrhea } \\
\text { Neutropenia }\end{array}$ & $\begin{array}{l}\text { Mucositis } \\
\text { Neutropenia } \\
\text { H-F syndrome }\end{array}$ \\
\hline
\end{tabular}

DI, dose intensity; DLTs, dose-limiting toxicities; pts, patients; 5-FU, 5-fluorouracil; CTP-11, irinotecan; LV, leucovorin; MTD, maximum tolerated dose.

No cases of febrile neutropenia or severe thrombocytopenia were observed. A few episodes of severe anemia were observed, and G3-4 mucositis and hand-foot syndrome occurred at the higher levels of administered 5-FU. Mild to moderate asthenia was common ( $41 \%$ of total cycles). No cases of thrombosis, embolic events, or other toxicities have been registered. No 60-day mortality, either directly or indirectly correlated to treatment, was observed at the different dose levels.

Table III shows the 5-FU received-DI (rDI) and the total dose administered: median $\mathrm{rDI} /$ cycle was $2000 \mathrm{mg} / \mathrm{m}^{2} / \mathrm{w}$ (range, 933-2400); average $\mathrm{rDI} /$ cycle was $1872 \mathrm{mg} / \mathrm{m}^{2} / \mathrm{w}$ with $<5 \%$ variability $(\alpha 0.05$, C.I. \pm 58$)$. Each patient had a median rDI of $1866 \mathrm{mg} / \mathrm{m}^{2} / \mathrm{w}$ (range, 1200-2300); the average $\mathrm{rDI}$ for each patient was $1850 \mathrm{mg} / \mathrm{m}^{2} / \mathrm{w}(\alpha 0.05$, C.I. \pm 102$)$.

Although tumor response was not the primary objective of this study, significant antitumor activity was seen. Patients were considered assessable for therapeutic response if they had measurable lesions and received more than 3 cycles. In 24 assessable patients, 3 complete and 6 partial responses were observed for an overall response rate of $37.5 \%(\alpha 0.05$, C.I. \pm 20$)$. Five patients had stable disease $(23 \%)$. Of the 9 responders, 3 had received a prior bolus 5-FU treatment and 6 were chemotherapy-naive. Sixteen patients had received a second-line oxaliplatin/5-FU treatment. At 17 months of median follow-up, we observed 21 deaths and 12 survivors.
The median time to progression (TTP) was 10 months (range, $2-28+$ ) and the median overall survival was 25 months (range, 3-42).

\section{Discussion}

The present data show that according to a 12 -h (10 p.m.10 a.m.) TFI, the RD intensity of 5-FU without LV modulation, is $2200 \mathrm{mg} / \mathrm{m}^{2} / \mathrm{w}$; this schedule is feasible and highly tolerable in an outpatient setting. Preliminary evaluation of the efficacy shows an objective response rate of $37.5 \%$ (C.I. $17.5-57.5 \%$ ) which is in the range of those reported by different groups proposing 5-FU infusion schedules plus CPT-11 (14,20-24).

The most common DLTs characterizing the present schedule are diarrhea and neutropenia as previously reported in phase I studies exploring different schedules of the same drugs (Table IV). Most of these studies include LV as a modulator of 5-FU infusion. The schedule proposed by Vanhoefer et al recommends a weekly x6 24-h 5-FU infusion $\left(2.6 \mathrm{~g} / \mathrm{m}^{2}\right)$ plus $\mathrm{LV}\left(500 \mathrm{mg} / \mathrm{m}^{2}\right)$ and CPT-11 $\left(80 \mathrm{mg} / \mathrm{m}^{2} / \mathrm{w}\right)$ followed by 1 week of rest (14). With respect to the present study, the latter regimen is characterized by an equivalent projected 5-FU/DI $\left(2267 \mathrm{mg} / \mathrm{m}^{2} / \mathrm{w}\right)$, and a lower CPT-11/DI for the 6 weeks of treatment. Diarrhea represented the main side effect at the MTD. In a schedule set by 
Ducreaux et al, fixed doses of bimonthly CPT-11 180$200 \mathrm{mg} / \mathrm{m}^{2}$ were associated with 5 -FU according to the de Gramont schedule (21). The most common cumulative G3-G4 toxicities per patient were diarrhea and G4 neutropenia, which in some cases was febrile. In a recent phase II study, this association confirmed the same toxicity profile (Ducreaux M, et al, Ann Oncol 13: abs. 2590, 2002). Two other studies proposing equivalent 5-FU/DI (1166-1167 mg/m²/w), as chronomodulated infusion and weekly C.I. associated to CPT-11/DI $108 \mathrm{mg} / \mathrm{m}^{2} / \mathrm{w}$ and $133 \mathrm{mg} / \mathrm{m}^{2} / \mathrm{w}$, respectively, showed a similar pattern of G3-G4 cumulative toxicity $(22,23)$.

At the RDs, none of the above-mentioned studies reports cases of dose-limiting diarrhea during the first cycle of treatment, but approximately $30 \%$ of patients experienced it during subsequent cycles. In studies by Garufi et al and Falcone et al, DLTs were not reported at the RDs; these 5-FU/CPT associations were characterized by the intensity of CPT-11 more than that of 5-FU (5-FU DI approximately 50\% lower than in the schedules by Vanhoefer et al and in the present study). In our study, no cases of dose-limiting diarrhea were observed among the 18 patients (38 cycles) treated at the RD for a median of 2 cycles (range 1-5). Dose-limiting mucositis, afebrile neutropenia and H-F syndrome occurred in $17 \%$ of patients (11\% of administered cycles).

As of today, no experimental evidence exists to support that LV modulation enhances the antitumoral activity of infusional 5-FU at its maximum tolerated dose. Two trials prospectively comparing infusional 5-FU vs. LV/bolus 5-FU stated that infusional $5-\mathrm{FU}$ is as effective as bolus 5-FU modulated by LV, but significantly less toxic except for diarrhea $(25,26)$. The ECOG study, exploring the effectiveness of 5-FU modulation, confirmed that G3-G4 diarrhea observed in the weekly 5 -FU infusion $\left(2.6 \mathrm{~g} / \mathrm{m}^{2} / \mathrm{w}\right)$ was consistently lower than in the LV modulated bolus 5-FU (13\% vs. 32$36 \%$ ), and the overall survival after a median follow-up of approximately 5 years did not differ significantly. Furthermore, preliminary data of a randomized study by Ducreaux et al show that high-dose 5-FU (2.6 g/ $\mathrm{m}^{2}$, weekly C.I.) appears to be equivalent in tolerability and 1-year survival to 5-FU bolus plus 5-FU infusion modulated by LV (high or low dose) (Ducreaux M, et al, Ann Oncol 13: abs. 2590, 2002).

Few studies have evaluated the combination of infusional 5-FU without LV modulation plus CPT-11, and none have actually addressed the issue concerning RDs of this association (21). In the present study, we recommend $85 \%$ of the 5 -FU/DI proposed by the ECOG study for infusional 5-FU used as a single agent. This 5-FU/DI is consistently higher than the threshold dose of 5-FU infusion $\left(1500 \mathrm{mg} / \mathrm{m}^{2} / \mathrm{w}\right)$ used in a clinical setting (3). Preliminary findings seem to suggest that LV could increase efficacy of infusional 5-FU alone, but is associated to G3/G4 diarrhea in $20 \%$ of cases (Schmoll H, et al, Proc Am Soc Clin Oncol 10: abs. 935, 2000). The EORTC study 40986 reports consistent toxicity and some instances of 60-day mortality using this schedule of LV and 5-FU (DI $2300 \mathrm{mg} / \mathrm{m}^{2} / \mathrm{w}$ ) in combination with CPT-11 (Köhne CH, et al, Proc Am Soc Clin Oncol 21: abs. 532, 2002).

In conclusion, the RD of TFI/5-FU using the described schedule falls within the range reported in the most intensive and active 5-FU schedules (5-FU/DI $2200 \mathrm{mg} / \mathrm{m}^{2} / \mathrm{w}$ ) for advanced CRC. Further studies are planned to explore doseresponse relationships of infusional 5-FU combinations with or without LV, as well as the more feasible and tolerable schedule of the more active 3-drug combination (5-FU, CPT-11 and oxaliplatin) in CRC.

\section{References}

1. Meta-Analysis Group in Cancer: Efficacy of intravenous continous infusion of fluorouracil compared with bolus administration in advanced colorectal cancer. J Clin Oncol 16: 301-308, 1998 .

2. Kohne CH, Schoffski P, Wilke H, et al: Effective biomodulation by leucovorin of high-dose infusion fluorouracil given as a weekly 24-hour infusion: Results of a randomized trial in patients with advanced colorectal cancer. J Clin Oncol 16: 418-426, 1998.

3. Sobrero A, Aschele C and Bertino JR: Fluorouracil in colorectal cancer: a tale of two drugs-implications for biochemical modulation. J Clin Oncol 15: 368-381, 1997.

4. Meta-Analysis Group in Cancer: Toxicity of fluorouracil in patients with advanced colorectal cancer: effect of administration schedule and prognostic factors. J Clin Oncol 16: 3537-3541, 1998.

5. Mayer RJ: Moving beyond fluorouracil for colorectal cancer. N Engl J Med 28: 963-964, 2000.

6. Machover D: A comprehensive review of 5-fluorouracil and leucovorin in patients with metastatic colorectal carcinoma. Cancer 80: 1179-1187, 1997.

7. Conti JA, Kemeny NE, Saltz LB, et al: Irinotecan is an active agent in untreated patients with metastatic colorectal cancer. J Clin Oncol 14: 709-715, 1996.

8. Rougier P, Bugat R, Douillard JY, et al: Phase II study of irinotecan in the treatment of advanced colorectal cancer in chemotherapy-naive patients and patients pretreated with fluorouracil-based chemotherapy. J Clin Oncol 15: 251-260, 1997.

9. Cunningham D, Pyrhonen S, James RD, et al: Randomised trial of irinotecan plus supportive care versus supportive care alone after fluorouracil failure for patients with metastatic colorectal cancer. Lancet 352: 1413-1418, 1998

10. Rougier P, Van Cutsem E, Bajetta E, et al: Randomised trial of irinotecan versus fluorouracil by continuous infusion after fluorouracil failure in patients with metastatic colorectal cancer. Lancet 352: 1407-1412, 1998.

11. Vanhoefer U, Harstrick A, Achterrath $\mathrm{W}$, et al. Irinotecan in the treatment of colrectal cancer: clinical overview. J Clin Oncol 19: 1501-1518, 2001.

12. Douillard JY, Cunningham D, Roth $\mathrm{AD}$, et al: Irinotecan combined with fluorouracil compared with fluorouracil alone as first-line treatment for metastatic colorectal cancer: A multicentre randomised trial. Lancet 355: 1041-1047, 2000.

13. Saltz LB, Cox JV, Blanke C, et al: Irinotecan plus fluorouracil and leucovorin for metastatic colorectal cancer. N Engl J Med 343: 905-914, 2000

14. Vanhoefer U, Harstrick A, Kohne CH, et al: Phase I study of a weekly schedule of irinotecan, high-dose leucovorin, and infusional fluorouracil as first-line chemotherapy in patients with advanced colorectal cancer. J Clin Oncol 17: 907-913, 1999.

15. Sobrero A, Kerr D, Glimelius B, et al: New direction in the treatment of colorectal cancer: a look to the future. Eur J Cancer 36: 559-566, 2000.

16. Lévi F: Chronopharmacology of anticancer agents. In Handbook of Experimental Pharmacology: Physiology and Pharmacology of Biological Rhythms-Cancer Chemotherapy. Redfern PH and Lemmer B (eds). Springer-Verlag, Berlin, pp299-301, 1997.

17. Harris BE, Song R, Soong SJ and Diasio RB: Relationship between dihydropyrimidine dehidrogenase activity and plasma 5-fluorouracil levels with evidence for circadian varation of enzyme activity and plasma drug levels in cancer patients receiving 5-fluorouracil by protracted continuous infusion. Cancer Res 50: 197-201, 1990.

18. Smaaland R, Abrahamsen JF, Svardal AM, et al: DNA cell cycle distrubution and glutathione (GSH) content according to circadian stage in bone marrow of cancer patients. Br J Cancer 66: 39-45, 1992 . 
19. Simon R, Freidlin B, Rubinstein L, et al: Accelerated titration designs for phase I clinical trials in oncology. J Natl Cancer Inst 89: 1138-1147, 1997.

20. Kakolyris S, Souglakos J, Kouroussis C, et al: A dose-finding study of irinotecan (CPT-11) plus a four-day continuous 5fluorouracil infusion in advanced colorectal cancer. Oncology 60: 207-213, 2001.

21. Ducreux M, Ychou M, Seitz JF, et al: Irinotecan combined with bolus fluorouracil, continuous infusion fluourouracil, and highdose leucovorin every two weeks (LV5FU2 regimen): a clinical dose-finding and pharmacokinetic study in patients with pretreated metastatic colorectal cancer. J Clin Oncol 17: 2901-2908, 1999.

22. Falcone A, Di Paolo A, Masi G, et al: Sequence effect of irinotecan and fluorouracil treatment on pharmacokinetics and toxicity in chemotheraphy-naive metastatic colorectal cancer patients. J Clin Oncol 19: 3456-3462, 2001.

23. Garufi C, Dogliotti L, D'Attino RM, et al: Irinotecan and chronomodulated infusion of 5-fluorouracil and folinic acid in the treatment of patients with advanced colorectal carcinoma. A phase I study. Cancer 91: 712-720, 2001.
24. Vamvakas L, Kakolyris S, Kouroussis C, et al: Irinotecan (CPT-11) in combination with infusional 5-fluorouracil and leucovorin (de Gramont regimen) as first-line treatment in patients with advanced colorectal cancer. A multicenter phase II study. Am J Clin Oncol 25: 65-70, 2002.

25. O'Dwyer PJ, Manola J, Valone FH, et al: Fluorouracil modulation in colorectal cancer: lack of improvement with N-phosphonoacetyl-1-aspartic acid or oral leucovorin or interferon, but enhanced therapeutic index with weekly 24-hour infusion schedule. An Eastern Cooperative Oncology Group/Cancer and Leukemia Group B Study. J Clin Oncol 19: 2413-2421, 2001.

26. Leichman CG, Fleming TR, Muggia FM, et al: A phase II study of fluorouracil and its modulation in advanced colorectal cancer: A Southwest Oncology Group study. J Clin Oncol 13: 1303-1311, 1995. 